Arch. Gerontol. Geriatr. Suppl. 1 (2007) 101-104

0167-4943/\$ - see front matter (C) 2007 Elsevier Ireland Ltd. All rights reserved.

\title{
PREVALENCE OF MAJOR DEPRESSIVE DISORDER AND DEMENTIA IN PSYCHOGERIATRIC OUTPATIENTS
}

\section{A. CHINELLO, B. GRUMELLI, C. PERRONE and G. ANNONI*}

University of Milan-Bicocca, Department of Clinical Medicine, Prevention and Sanitary Biotechnology, Division of Geriatrics, San Gerardo Hospital (Monza), I-20052 Monza, Italy

*Corresponding author:

Tel.:+(39-039)-233-3475-4358, Fax+(39-039)-233.2220 E-mail: giorgio.annoni@unimib.it

\section{SUMMARY}

The relationship between depression and dementia in the elderly has been widely investigated, but the real interplay between these variables is still not clear. This observational study highlights the influence of some basic variables, such as sex and age, in the development of dementia and major depression. It shows (i) the importance of sex in the age of onset of depression and dementia, (ii) the presence of two types of depressive syndrome, the first linked to the development of dementia, the second as reactive depression; (iii) the need for more attention to depressive symptoms in young-elderly men.

Keywords: dementia in elderly, major depressive disorder

\section{INTRODUCTION}

Neuroimaging studies in geriatric patients suggest that both the duration and number of past episodes of major depressive disorder (MDD) are associated with a significant loss of volume in the hippocampus (Rapp et al., 2006). This probably depends on changes in neuro-genesis because of high levels of stress. Evidence is also emerging that patients with Alzheimer's disease (AD) and a lifetime history of MDD suffer faster cognitive decline than patients with AD but no history of MDD (Clark et al., 1998; Ebmeier et al., 1998; Ownby et al., 2006). Therefore, MDD may raise the overall risk of developing degenerative dementia, especially $A D$, but also vascular forms.

Clinically, individuals with MDD show impairments in episodic memory, mental flexibility and information processing (Steffens et al., 2006). Two different hypotheses link dementia and MDD: the first considers the depressive symptoms as prodromic for the development of dementia, while the second views the depression as an independent risk factor for dementia (Ganguli et al., 2006). The relationship between depressive symptoms and cognitive decline is, however, extremely complex because it is influenced by many variables such as age, sex, social conditions, and observational setting.

This descriptive study investigated the links between depression and dementia through an analysis of basic variables such as sex and age. 


\section{SUBJECTS AND METHODS}

We retrospectively examined the database of the psychogeriatric outpatients referred to the S. Gerardo Hospital of Monza (Italy) during the period 2000-2005. A total of 555 patients were analyzed with a descriptive statistics method for age, sex and diagnostic category (DC). Five DCs were established, taking into account the temporal links: DC 1 included only dementia, and DC 5 subjects with depression (MDD). There were three mixed DCs: subjects with first dementia and then MDD (DC 2); patients with first MDD and then dementia (DC 4); DC 3 comprised patients with dementia and MDD, but no clear temporal link between the two.

Dementia was identified for patients with a mini mental state examination (MMSE) score $<24 / 30$ (Folstein et al., 1975), and MDD for Cornell scale >12 (Alexopoulos et al., 1988), and geriatric depression scale (GDS) $>14$ (Sutcliffe et al., 2000). In the mixed diagnosis categories (DC 2, 4), there was a gap of at least 60 days between the diagnoses of dementia and MDD; this criterion did not apply for DC 3 . The diagnosis of dementia was for degenerative, vascular or mixed forms (DSM IV: 294.xx, 290.xx, 331.0) (APA, 2000), while patients with a major depressive disorder were classified as having MDD (DSM IV: 296.2x, 296.3x) (APA, 2000).

\section{RESULTS}

Overall, $71.7 \%$ were women, and the mean age for the whole case list was 81.7 years; 332 patients had dementia (DC 1: 59.8\%), 130 MDD (DC 5: 23.4\%), 93 mixed diagnoses (DCs 2, 3 or $4: 16.8 \%$ ). In $41.9 \%$ of the patients in this last group $(7.0 \%$ of the whole sample) we initially identified MDD (DC 4), while in $21.5 \%$ (3.6\% of the total) dementia was found first (DC 2) and $36.6 \%$ (6.1\% of the total) were DC 3 .

Table I

MEAN AGES FOR DIAGNOSTIC CATEGORIES (DC) AND SEX.

\begin{tabular}{lccccc}
\hline & DC & Age (years) & M & F & (M-F) \\
\hline Dementia only & 1 & 83 & 81 & 83 & -2 \\
Dementia, MDD & 2 & 80 & 80 & 79 & +1 \\
Dementia + MDD & 3 & 79 & 78 & 79 & -1 \\
MDD, dementia & 4 & 81 & 79 & 81 & -3 \\
MDD only & 5 & 80 & 81 & 80 & +1 \\
\hline
\end{tabular}

There was a substantial age difference for dementia and depression ( 83 versus 80 years), and between only dementia and dementia with subsequent MDD (83 versus 80 years), while the DC 3 patients were younger (79 years). 
The mean age of female patients was 82 years (with high frequency of patients with 83 years), and the mean age of males was 81 years (with high frequency of patients with 78 years). The main age difference by sex was in DC 1 (83 years for females, 81 years for males, with a difference of two years) and for DC 4 (81 years for females, 79 years for males, with a difference of three years) (Table I)

Analyzing the distribution of diagnoses by sex (Table II), there were more female DC 1 patients (only dementia) than males $(60.8 \%$ vs. $57.3 \%)$; the opposite was true for DC 3 (5.3\% females vs. $8.3 \%$ males). The distribution of males in DCs $1,2,4$ and 5 (27.1, 25.0, 28.2 and $29.2 \%$, respectively) is in line with the general data $(28.3 \%)$, but the percentage of DC 3 males was larger than in the other categories (38.2\%, age difference $10 \%)$.

Table II

THE SEX-DISTRIBUTION OF PREVALENCE OF DIAGNOSES

$\left.\begin{array}{lcccc}\hline & \text { DC } & \text { Male } \% & \text { Female } \% & \% \text { of total } \\ \hline \text { Dementia only } & 1 & 57.3 & 60.8 & 59.8 \\ \text { Dementia, MDD } & 2 & 3.2 & 3.8 & 3.6 \\ \text { Dementia + MDD } & 3 & 8.3 & 5.3 & 6.1 \\ \text { MDD, dementia } & 4 & 7.0 & 7.0 & 7.0 \\ \text { MDD only } & 5 & 24.2 & 23.1 & 23.4\end{array}\right\} 16.8$

\section{DISCUSSION}

In our study-population, the proportions of females is higher than of the males, as it suggests by $71 \%$ female patients; in addition dementia was the most frequent diagnosis in this group (59.8\%), with MDD some distance behind (23.4\%). Among the mixed cases, MMD occurred more frequently before dementia (7\%) than after it $(3.6 \%$, Table II). Two different types of depression can be distinguished: the first (DC 4) considers depressive symptoms as a risk factor/prodrome for dementia while the second views MMD (DC 2) as an adaptive and reactive disorder influenced by the patient's insight about the cognitive deficits. In these last groups (DCs 2 and 4 ) the mean age was slightly lower than the overall series with only dementia ( 80 and 81 years vs. 83 years), especially for women; so depressive symptoms seem to decrease with aging. Another important difference concerns the sex: the mean ages for dementia and depression in women differed more than for men ( 83 and 80 years for females; 81 and 81 years for males). Possibly the shorter life expectancy of men causes a shorter "time window" (gap) for dementia and MMD and for the age at onset. 
Another consideration emerges for DC 3, where there was a larger proportion of male patients ( $38 \%$ vs. $28.3 \%$ overall). Considering the lower age for DC 3 (79 years) and the high rate of males, the results suggest it may be more difficult to diagnose MDD in youngelderly males. This problem may be influenced by the complex relationships between sex, personality and social conditions, which can hide depressive symptoms.

Taken together, these data indicate: (i) the role of sex in the age at onset of depression and dementia, (ii) the presence of two types of depressive syndrome, the first linked to the development of dementia, the second a reactive depression; (iii) the need for close attention to depressive symptoms in young-elderly men.

\section{REFERENCES}

Alexopoulos, G.S, Abrams, R.C, Young, R.C. and Shamoian, C.A. (1988): Cornell scale for depression in dementia. Biol. Psychiatry, 23, 271-284.

APA (American Psychiatric Association) (2000): Diagnostic and Statistical Manual of Mental Disorders, Fourth Edition, Text Revision, DSM IV-TR, APA Press, Washington, D.C.

Clark, L.M., McDonald, W.M., Welsh-Bohmer, K.A., Siegler, I.C., Dawson, D.V., Tupler, L.A. and Krishnan, K.R. (1998): Magnetic resonance imaging correlates of depression in early- and late-onset Alzheimer's disease. Biol. Psychiatry, 44, 592-599.

Ebmeier, K.P., Glabus, M.F., Prentice, N., Ryman, A. and Goodwin, G.M. (1998): A voxelbased analysis of cerebral perfusion in dementia and depression of old age. Neuroimage, 7, 199-208.

Folstein, M.F., Folstein, S.E. and McHugh, P.R. (1975): Mini-Mental State: A practical method for grading the state of patients for the clinician, J. Psych. Res., 12, 189-198.

Ganguli, M., Yangchun, D., Dodge, H., Ratcliff, G. and Chang, C. (2006): Depressive symptoms and cognitive decline in late life: A prospective epidemiological study. Arch. Gen. Psychiatry, 63, 153-160.

Ownby; R.L., Crocco, E., Acevedo, A., John, V. and Loewenstein, D. (2006): Depression and risk for Alzheimer disease: Systematic review, meta-analysis, and metaregression analysis. Arch. Gen. Psychiatry, 63, 530-538.

Rapp, M.A., Schnaider-Beeri, M., Grossman, H.T., Sano, M., Perl, D.P., Purohit, D.P., Gorman, J.M. and Haroutunian, V. (2006): Increased hippocampal plaques and tangles in patients with Alzheimer disease with a lifetime history of major depression. Arch. Gen. Psychiatry, 63, 161-167.

Steffens, D.C; Otey, E., Alexopoulos, G.S., Butters, M.A., Cuthbert, B., Ganguli, M., Geda, Y.E., Hendrie, H.C., Krishnan, R.R., Kumar, A., Lopez, O.L., Lyketsos, C.G., Mast, B.T., Morris, J.C., Norton, M.C., Peavy, G.M., Petersen, R.C., Reynolds, C.F., Salloway, S., Welsh-Bohmer, K.A. and Yesavage, J. (2006): Perspectives on depression, mild cognitive impairment, and cognitive decline. Arch. Gen. Psychiatry, 63, 130-138.

Sutcliffe, C., Cordingley, L., Burns, A., Mozley, C.G., Bagley, H., Huxley, P. and Challis, D. (2000): A new version of the geriatric depression scale for nursing and residential home populations: the geriatric depression scale (GDS-12R). Int. Psychogeriatr. J., $12,173-181$. 